\title{
Changes in Opacification of Hydrophobic Acrylic Intraocular Lenses According to Temperature and Hydration
}

This article was published in the following Dove Press journal: Clinical Ophthalmology

\author{
Jung Youb Kang $\mathbb{D}^{1, *}$ \\ Ju Hwan Song ${ }^{2} *$ \\ Sang Joon Lee (iD)
}

'Department of Ophthalmology, Kosin University College of Medicine, Busan, South Korea; ${ }^{2}$ The Bom Eye Clinic, Busan, South Korea

*These authors contributed equally to this work
Correspondence: Sang Joon Lee Department of Ophthalmology, Gospel Hospital, Kosin University College of Medicine, 262, Gam Cheon-ro, Seo-gu, Busan 49267, South Korea

Tel +82-5I-990-6I 40

Fax +82-5I-990-3026

Email hhiatus@gmail.com
Purpose: To investigate optic opacification of hydrophobic acrylic intraocular lens (IOL) depending on hydration and temperature conditions.

Methods: IOL (Acrysof ${ }^{(B)}$ MA60BM Alcon, Fort Worth, Texas, USA) extracted from a 55year-old male who underwent binocular cataract 11 years ago were used for the analysis. On slit lamp examination, the binocular IOL optics showed homogenous opacification. After extraction of the IOLs, the IOL opacification disappeared during dry storage at $4{ }^{\circ} \mathrm{C}$. To investigate the changes in IOL opacification according to temperature and hydration, an extracted IOL was stored in either dry conditions or normal saline at $4{ }^{\circ} \mathrm{C}$, room temperature, or $37^{\circ} \mathrm{C}$ for 24 hours, and then the degree of haziness was examined. To investigate the impact of an opaque optic on visual function, light transmission was performed using an ultraviolet-visible spectrophotometer (U-3000, Hitachi High-Technologies Corp., Tokyo, Japan).

Results: The extracted IOL optics at $4^{\circ} \mathrm{C}$, room temperature, and $37^{\circ} \mathrm{C}$ were transparent at dry conditions. When the dried IOL was immersed in normal saline at room temperature and $37^{\circ} \mathrm{C}$, opacification appeared. However, when the dried IOL was immersed in normal saline at $4^{\circ} \mathrm{C}$, opacification of the IOL did not appear. When compared with the control, light transmission of the extracted IOLs from the right and left eyes stored in $37^{\circ} \mathrm{C}$ normal saline decreased by $4.7 \%$ at $453 \mathrm{~nm}$ and by $5.1 \%$ at $482 \mathrm{~nm}$, respectively.

Conclusion: In acrylic hydrophobic IOLs, optic opacification can occur depending on temperature and hydration conditions.

Keywords: intraocular lens, whitening, scattering, opacification, hydrophobic lens, acrylic lens

\section{Introduction}

With the increased frequency of small-incision cataract surgery, the use of foldable soft intraocular lenses (IOLs) is expanding. Among foldable soft IOLs, hydrophobic acrylic intraocular lens (IOL) is widely used because of their convenience of insertion through a small incision, good visual rehabilitation, and low incidence of posterior capsular opacity (PCO). ${ }^{1,2}$ However, several studies have reported opacification, glistening, and scattering of hydrophobic acrylic IOLs. ${ }^{3-5}$

For this reason, the decrease in light transmittance is an important issue because it can affect visual function. ${ }^{6}$ Many of these problems have been reported for hydrophilic acrylic IOLs ${ }^{7-11}$ and are not currently used, but relatively few reports have been made for hydrophobic acrylic IOLs. ${ }^{3,5,6}$ Interestingly, all of these have 
been reported in Japan, and most of them reported decreased contrast sensitivity or visual acuity due to surface scattering of hydrophobic acrylic lenses.

According to what has been found so far, a couple of laboratory studies have shown that nanoglistening occurs on the subsurface of hydrophobic acrylic lenses, resulting in opacification of lens optic. ${ }^{12,13}$ Nanoglistening, which is caused by hydration of the components of the intraocular lens, mainly occurs in the subsurface region of the lens optic. That is, it is reported that it occurs intensively in the area close to the surface of the cross-section of the optic, and has no effect on the center of the cross-section. Until now, no reports have been found on the opacification of the central section of the hydrophobic acrylic IOL optic, not the surface.

Therefore, the researchers report that opacification can occur in the center of the cross-section of hydrophobic acrylic lenses, and that opacification can disappear or occur depending on temperature as well as the effect of hydration.

\section{Materials and Methods}

This study was conducted with the approval of the Institutional Review Board of Kosin University Gospel Hospital, South Korea (2018-07-038). Written informed consent for academic publication from the affected individual was obtained.

A 55-year-old male who underwent binocular cataract extraction with IOL (Acrysof ${ }^{\circledR}$ MA60BM) implantation 11 years previously presented with binocular decreased visual acuity. His past medical history was significant for a 20 -year history of diabetes mellitus and a 17-year history of hypertension. His medications included an insulin pump for glucose control and anti-hypertensive drugs. In the initial examination, his best corrected visual acuity (BCVA) values of the right and left eyes were 0.1 and 0.32 , respectively, with the Snellen visual acuity chart. Through slit lamp examination, we found binocular homogeneous ground glass opacity of the IOL optics in the bag without glistening (Figure 1). Binocular diabetic retinopathy and panretinal photocoagulation scars were also observed. Compared to the patient's previous record, no interval change was noted, except for the aforementioned opaque optics of the IOLs. Therefore, we performed IOL exchange in the left eye, which showed a greater decrease in visual acuity.

After administration of retrobulbar anesthesia, we dissected synechiae between the anterior capsule and haptics of the IOL using a Sinskey hook and $1.5 \%$ sodium hyaluronate (Kukje hyaluronic acid eye inj ${ }^{\circledR}$, Kukje Pharmaceutical Industrial, Korea), and we explanted the IOL after partial cutting of the IOL optic and haptic using Vannas scissors. Then, a hydrophobic acrylic IOL (HOYA iSert ${ }^{\circledR}$ Preloaded IOL system, HOYA Surgical Optics, Tokyo, Japan) was inserted into the ciliary sulcus. Five weeks after surgery on the left eye, IOL (HOYA iSert ${ }^{\circledR}$ Preloaded IOL system, HOYA Surgical Optics, Tokyo, Japan) exchange was performed in the right eye using the same procedure.

After storage of the extracted $\mathrm{IOL}$ at $4^{\circ} \mathrm{C}$ in a refrigerator, the opacification of the optic disappeared. In order to investigate the effects of temperature and hydration
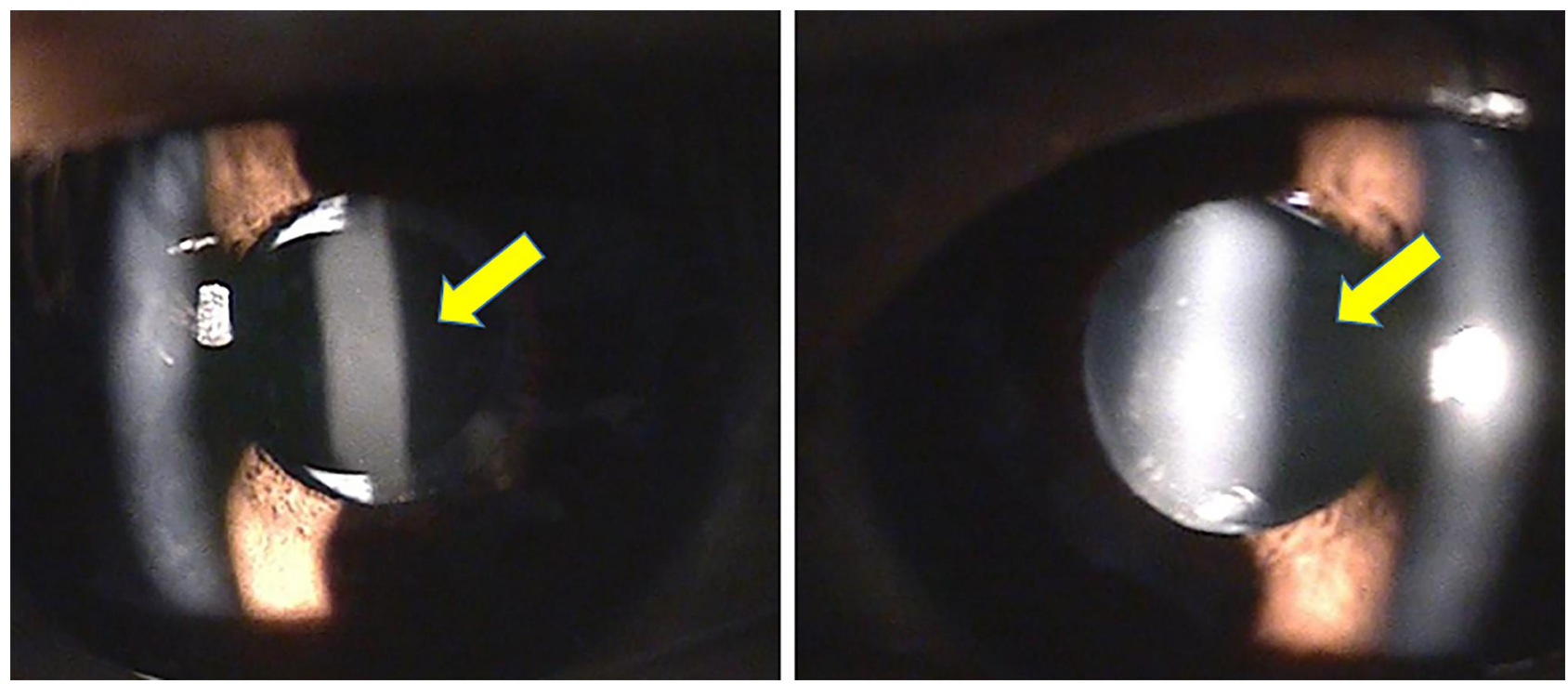

Figure I Preoperative anterior segment photographs. Left photo is the right eye, and right photo is the left eye. Anterior segment photographs showed ground glass opacification of the intraocular lense optics without definite glistening, and opacification in the left eye (right photo) was more severe. 
on opacity of the IOL, we examined the transparency of IOL optics at $4^{\circ} \mathrm{C}$, room temperature, and $37^{\circ} \mathrm{C}$ in dry conditions and in normal saline after storage for 24 hours. The reason for designing each temperature condition is as follows. The lower temperature, $4^{\circ} \mathrm{C}$, is a sufficiently low temperature that can be easily controlled by a refrigerator. Room temperature refers to the temperature at which the IOL is usually stored, and $37^{\circ} \mathrm{C}$ correlates with normal body temperature.

To investigate the impact of opaque optics on visual function, light transmission was performed using an Ultraviolet-Visible Spectrophotometer (U-3000, Hitachi High-Technologies Corp., Tokyo, Japan). Using the same material IOL (Acrysof ${ }^{\circledR}$ SA60AT, Alcon Lab., Fort Worth, TX, USA) as a control, we analyzed the differences in light transmission between a dry-stored IOL and the $37^{\circ} \mathrm{C}$ normal saline-stored, extracted IOL.

\section{Results}

After surgery, we noted transparent IOLs from each of the patient's eyes (Figure 2). BCVA values of the right and left eyes improved to 0.125 and 0.5 from 0.1 and 0.32 , respectively.

A transparent IOL optic was observed at $4^{\circ} \mathrm{C}$, room temperature, and $37^{\circ} \mathrm{C}$ in both dry conditions and in $4{ }^{\circ} \mathrm{C}$ normal saline (Figures 3A-D and 4A-D). However, an opaque IOL optic was observed at room temperature and $37^{\circ} \mathrm{C}$ in normal saline (Figures 3E, F and 4E, F). In the absence of water, there was no difference in the occurrence of haziness independent of the ambient temperature, but haziness occurred at higher temperatures in the presence of water.
When compared with the control, the light transmission of the extracted IOLs stored in $37^{\circ} \mathrm{C}$ normal saline of the right and left eyes decreased by $4.7 \%$ at $453 \mathrm{~nm}$ and by $5.1 \%$ at $482 \mathrm{~nm}$, respectively (Figure 5).

\section{Discussion}

Various mechanisms can cause opacification of an IOL. Lens epithelial deposits on the surface of the IOL can cause scattering of light, ${ }^{14}$ or water molecules can enter the three-dimensional structure of the IOL to cause glistening or whitening. ${ }^{4,5,15}$ Glistening appears as bright spots throughout the entire IOL optic, whereas whitening shows as opacification of the IOL optic surface.

The whitening phenomenon has been well studied in Japan. Matsushima et $\mathrm{al}^{3}$ studied light scattering on or under an IOL surface with glistening in the optical part of Acrysof ${ }^{\circledR}$ MA60BM and MA60BA IOLs and found that whitening of the optic part disappeared when the extracted IOLs were dried, but whitening re-occurred in physiological saline. They hypothesized that water retained in voids within the polymer network of the IOL undergoes phase separation in both glistening and whitening. In whitening, water aggregates are much smaller than in glistening but are still of sufficient size to cause scattering of visible light. This leads to white opacification. This whitening was mainly observed on the surface of the optic. And through subsequent experimental studies, it was revealed that nanoglistenings were gathered to form this whitening, which looked like opacification. ${ }^{12,13}$

We found some differences in the appearance of whitening in the present study when compared to the
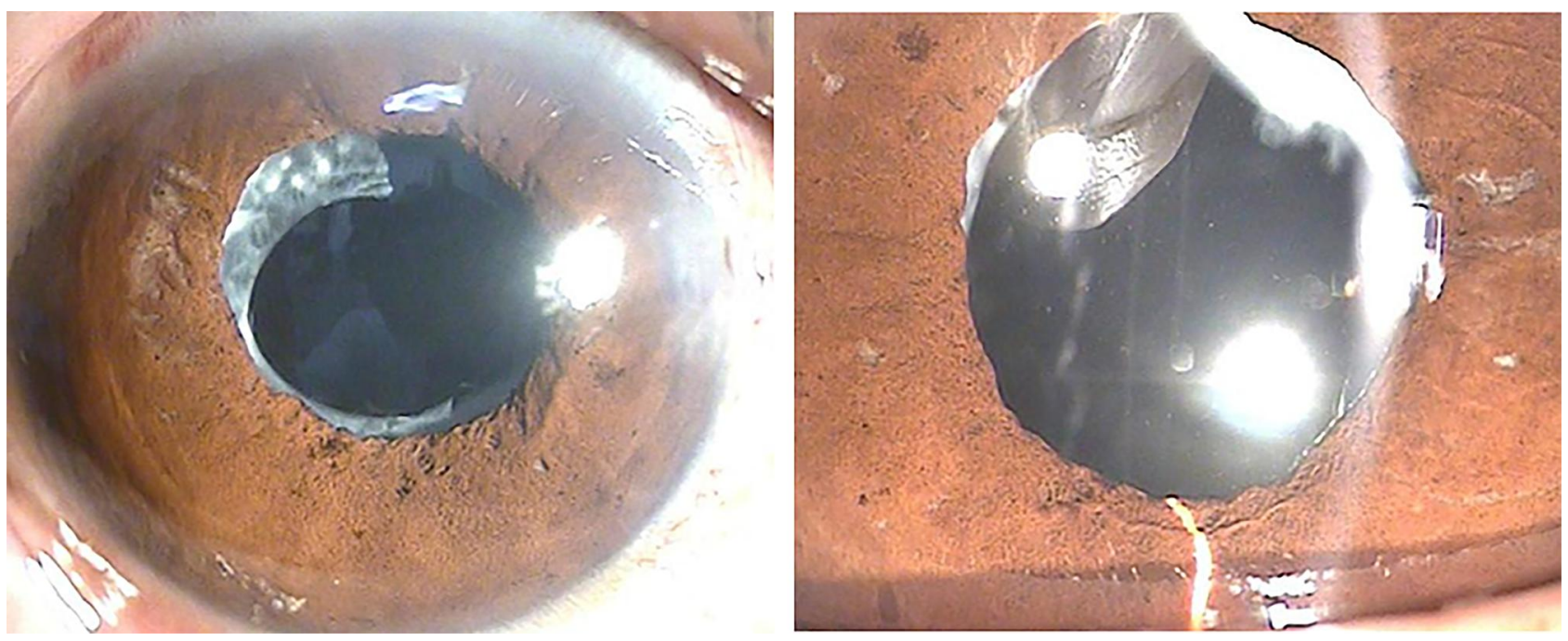

Figure 2 Anterior segment photographs after intraocular lens exchange. Left photo is the right eye, and right photo is the left eye. Anterior segment photographs showed a clear intraocular lens without optic opacification. 

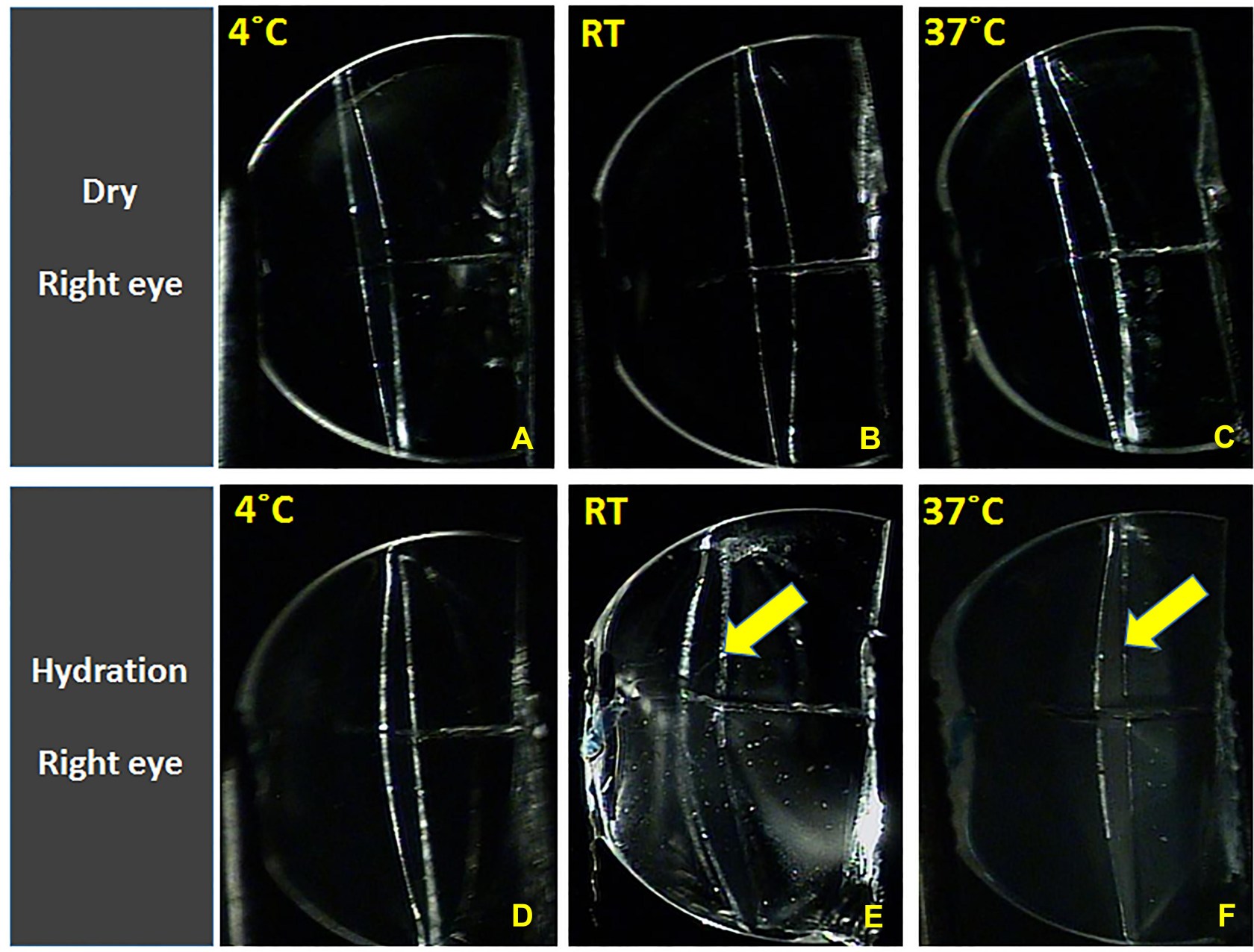

Figure 3 Photographs of the right $\mathrm{IOL}$ by slit lamp microscopy according to temperature and hydration. $\mathrm{A}$ transparent $\mathrm{IOL}$ optic was observed at $4^{\circ} \mathrm{C}(\mathbf{A})$, room temperature (B), and $37^{\circ} \mathrm{C}(\mathbf{C})$ in dry conditions and in $4^{\circ} \mathrm{C}$ normal saline (D). However, an opaque IOL optic was observed at room temperature (E) and $37^{\circ} \mathrm{C}(\mathbf{F})$ in normal saline. $\mathrm{RT}=$ room temperature.

previous studies described whitening of an IOL from surface light scattering. In this study, the whitening phenomenon was uniformly observed inside, rather than on the surface, of the IOL. Ong et $\mathrm{al}^{12}$ reported that the whitening phenomenon is caused by a type of nanoglistenings (subsurface nanoglistenings), and the subsurface nanoglistenings can be seen at various depths from the IOL surface. Based on the study by Marcia et al, we believe that the subsurface nanoglistenings shown in this study were located deeper from the IOL surface than the nanoglistenings from the Japanese study, so the whitening appeared to be more inside.

Yoshida et $\mathrm{al}^{6}$ reported that a small reduction (4\%) of light transmission did not significantly affect visual acuity, but a large decrease (16.3\%) in light transmission affected visual acuity. However, in the present study, the patient presented with decreased visual acuity despite a slight decrease $(4.7 \%$ in the right eye and $5.1 \%$ in the left eye) in light transmission compared to the control IOL, and postoperative subjective visual improvement was evident. Therefore, it is unclear how IOL opacity affects subjective visual symptoms, and further studies are needed.

Matsushima et $\mathrm{al}^{3}$ observed the occurrence of Acrysof ${ }^{\circledR}$ IOLs opacity at room temperature in a dry condition and in physiological saline. So, the temperature and moisture conditions were not completely controlled. As a result, there is a limitation to evaluate the effect of temperature changes on the occurrence of opacification under the same hydration and the effect of water presence on opacification at the same temperature. The investigation by Yoshida et $\mathrm{al}^{6}$ was conducted only at room temperature and at $33^{\circ} \mathrm{C}$ in physiological saline, and the effects of changes in temperature and hydration on the development of opacification could not be independently assessed. On 

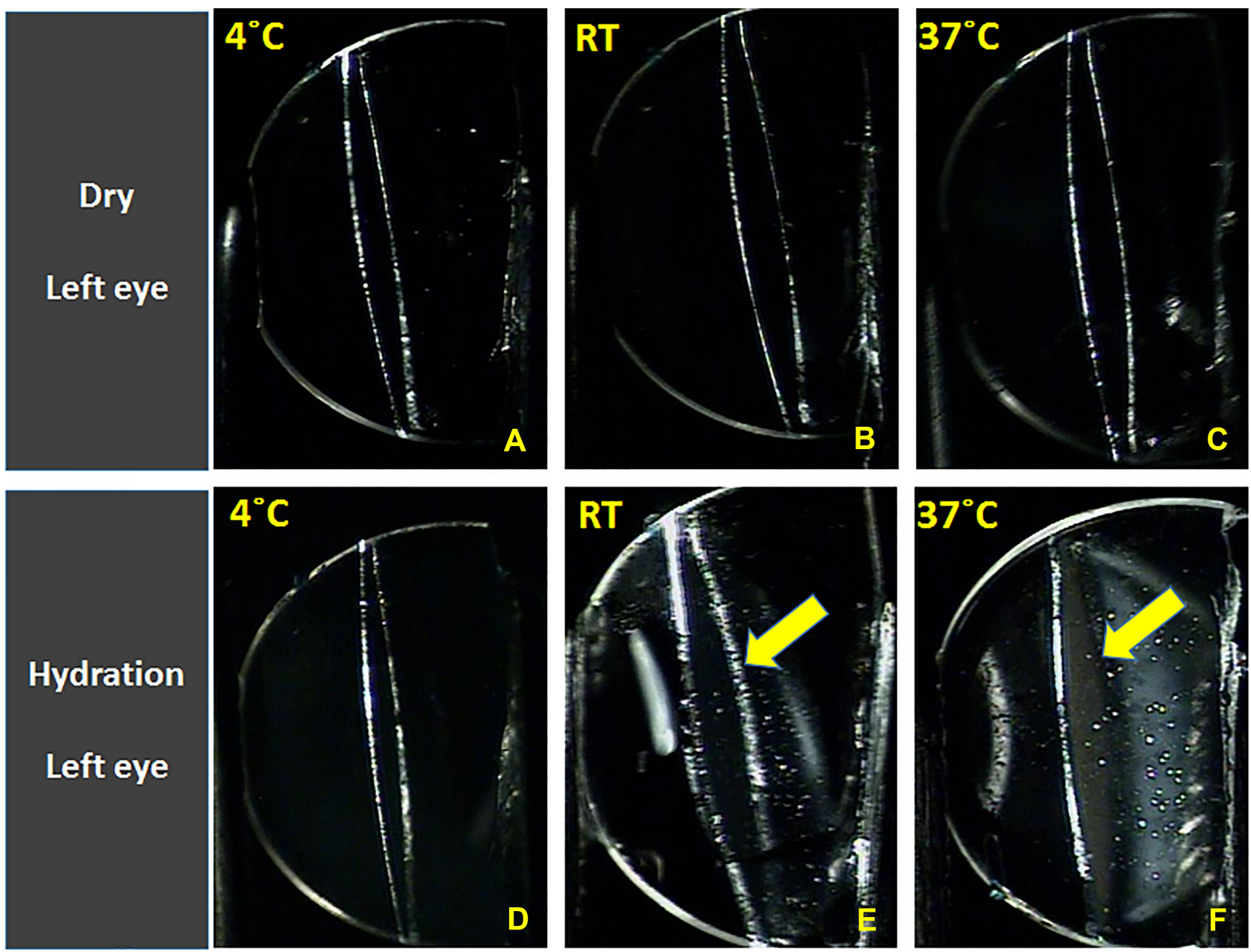

Figure 4 Photographs of the left IOL by slit lamp microscopy according to temperature and hydration. $\mathrm{A}$ transparent $\mathrm{IOL}$ optic was observed at $4^{\circ} \mathrm{C}(\mathrm{A})$, room temperature $(\mathbf{B})$, and $37^{\circ} \mathrm{C}(\mathbf{C})$ in dry conditions and in $4^{\circ} \mathrm{C}$ normal saline (D). However, an opaque $\mathrm{IOL}$ optic was observed at room temperature $(\mathbf{E})$ and $37^{\circ} \mathrm{C}(\mathbf{F})$ in normal saline. $\mathrm{RT}=$ room temperature.

the other hand, in the present study, only the temperature was changed under the same hydration in order to investigate the effect of temperature on the occurrence of opacification. Similarly, in order to assess the occurrence of opacification according to hydration, only the presence of water was changed under the same temperature condition. In this respect, this study is significant in that each effect can be confirmed independently; we confirmed that opacification was not induced by changes in temperature under dry conditions at $4{ }^{\circ} \mathrm{C}$ to $37^{\circ} \mathrm{C}$, but the degree of opacification increased as the temperature increased in the presence of water.

In the present study, the patient had diabetes, which could have led to a change in the blood-aqueous barrier, and the aqueous humor component might have been different from that of a normal person. ${ }^{16}$ In addition, there was a difference in the degree of opacification between the bilateral IOLs, which also could have affected the components and temperature of the aqueous humor. It is still unclear why the IOL, which maintained transparency immediately after surgery, was affected by hydration over time, and it is necessary to investigate whether there is any association with systemic diseases or aqueous humor components.

In hydrophobic acrylic intraocular lenses, which are optically superior and widely used today, it has been demonstrated that whitening, which looks like opacification, can occur even in the center of the cross-section of the IOL optic, and whether or not such whitening occurs can vary depending on hydration and temperature. Considering the long-term outcome of cataract surgery, improvement in IOL materials and research on their physical properties are needed. 

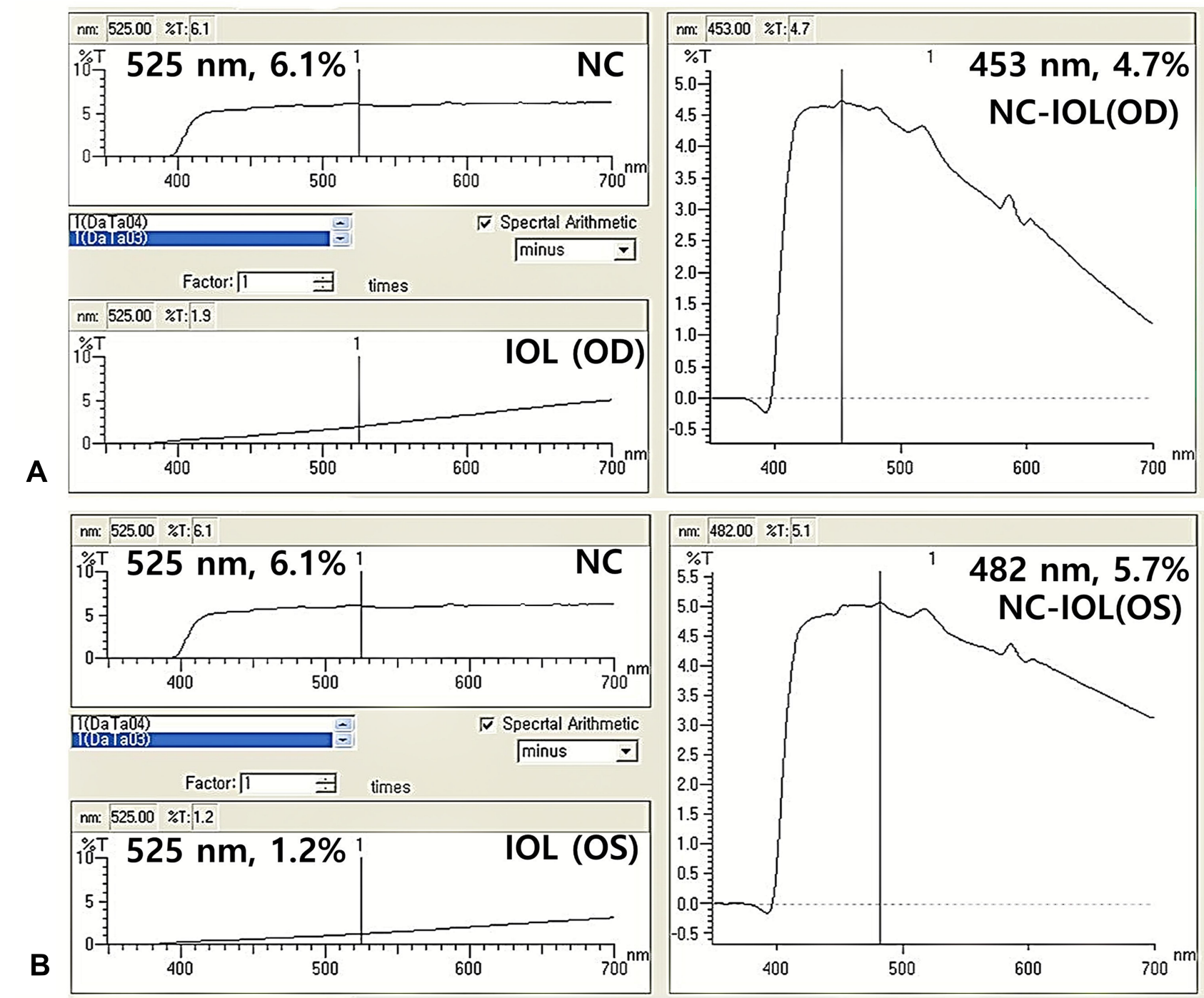

Figure 5 Differences of light transmission between a normal control IOL (Acrysof ${ }^{\circledR}$ SA60AT) stored dry at room temperature and an extracted IOL stored in $37^{\circ} \mathrm{C}$ normal saline by an ultraviolet-visible spectrophotometer. Light transmission of the extracted IOL stored in $37^{\circ} \mathrm{C}$ normal saline of the right (A) and left (B) eyes decreased by $4.7 \%$ at $453 \mathrm{~nm}$ and by $5.1 \%$ at $482 \mathrm{~nm}$, respectively, compared with the normal control (NC).

\section{Disclosure}

The authors reported they have no potential conflicts of interest relevant to this article.

\section{References}

1. Ursell PG, Spalton DJ, Pande MV. Anterior capsule stability in eyes with intraocular lenses made of poly(methyl methacrylate), silicone, and AcrySof. J Cataract Refract Surg. 1997;23(10):1532-1538. doi:10.1016/S0886-3350(97)80025-9

2. Hollick EJ, Spalton DJ, Ursell PG, Pande MV. Biocompatibility of poly(methyl methacrylate), silicone, and AcrySof intraocular lenses: randomized comparison of the cellular reaction on the anterior lens surface. J Cataract Refract Surg. 1998;24(3):361-366. doi:10.1016/ S0886-3350(98)80324-6

3. Matsushima H, Mukai K, Nagata M, Gotoh N, Matsui E, Senoo T. Analysis of surface whitening of extracted hydrophobic acrylic intraocular lenses. J Cataract Refract Surg. 2009;35(11):1927-1934. doi:10.1016/j.jcrs.2009.07.004
4. Miyata A, Yaguchi S. Equilibrium water content and glistenings in acrylic intraocular lenses. $J$ Cataract Refract Surg. 2004;30 (8):1768-1772. doi:10.1016/j.jcrs.2003.12.038

5. Nishihara H, Yaguchi S, Onishi T, Chida M, Ayaki M. Surface scattering in implanted hydrophobic intraocular lenses. J Cataract Refract Surg. 2003;29(7):1385-1388. doi:10.1016/S0886-3350(02) 01994-6

6. Yoshida S, Matsushima H, Nagata M, Senoo T, Ota I, Miyake K. Decreased visual function due to high-level light scattering in a hydrophobic acrylic intraocular lens. Jpn J Ophthalmol. 2011;55 (1):62-66. doi:10.1007/s10384-010-0901-2

7. Dick HB, Tehrani M, Brauweiler P, Haefliger E, Neuhann T, Scharrer A. [Complications of foldable intraocular lenses requiring explantation. Results of the 2000 and 2001 survey in Germany]. Ophthalmologe. 2003;100(6):465-470. doi:10.1007/s00347-0020775-x. German.

8. Fernando GT, Crayford BB. Visually significant calcification of hydrogel intraocular lenses necessitating explantation. Clin Experiment Ophthalmol. 2000;28(4):280-286. doi:10.1046/j.14429071.2000.00331.x 
9. Mamalis N. Complications of foldable intraocular lenses requiring explantation or secondary intervention-2001 survey update. $J$ Cataract Refract Surg. 2002;28(12):2193-2201. doi:10.1016/ s0886-3350(02)01612-7

10. Mamalis N, Davis B, Nilson CD, Hickman SM, LeBoyer RM. Complications of foldable intraocular lenses requiring explantation or secondary intervention-2003 survey update. J Cataract Refract Surg. 2004;30(10):2209-2218. doi:10.1016/j.jcrs.2004.06.051

11. Neuhann IM, Kleinmann G, Apple DJ, New A. Classification of Calcification of Intraocular Lenses. Ophthalmology. 2008;115 (1):73-79. doi:10.1016/j.ophtha.2007.02.016

12. Ong MD, Callaghan TA, Pei R, Karakelle M. Etiology of surface light scattering on hydrophobic acrylic intraocular lenses. J Cataract Refract Surg. 2012;38(10):1833-1844. doi:10.1016/j. jers.2012.05.043
13. Matsushima H, Katsuki Y, Mukai K, Nagata M, Senoo T. Observation of whitening by cryo-focused ion beam scanning electron microscopy. J Cataract Refract Surg. 2011;37(4):788-789. doi:10.1016/j.jcrs.2011.01.014

14. Fukaya Y, Hara T, Hara T, Iwata S. Light scattering caused by cells on the intraocular lens. J Cataract Refract Surg. 1988;14(4):396-399. doi:10.1016/S0886-3350(88)80146-9

15. Miyata A, Uchida N, Nakajima K, Yaguchi S. Clinical and Experimental Observation of Glistening in Acrylic Intraocular Lenses. Jpn J Ophthalmol. 2000;44(6):693. doi:10.1016/S00215155(00)00257-4

16. Lee D-H, Seo Y, Joo C-K. Progressive opacification of hydrophilic acrylic intraocular lenses in diabetic patients. $J$ Cataract Refract Surg. 2002;28(7):1271-1275. doi:10.1016/S0886-3350(02)01245-2
Clinical Ophthalmology

\section{Publish your work in this journal}

Clinical Ophthalmology is an international, peer-reviewed journal covering all subspecialties within ophthalmology. Key topics include: Optometry; Visual science; Pharmacology and drug therapy in eye diseases; Basic Sciences; Primary and Secondary eye care; Patient Safety and Quality of Care Improvements. This journal is indexed on PubMed

Submit your manuscript here: https://www.dovepress.com/clinical-ophthalmology-journal
Dovepress

Central and CAS, and is the official journal of The Society of Clinical Ophthalmology (SCO). The manuscript management system is completely online and includes a very quick and fair peer-review system, which is all easy to use. Visit http://www.dovepress.com/ testimonials.php to read real quotes from published authors. 